\title{
Relationship of Gallbladder Diseases with Sociodemographic Characteristics, Lifestyle, and Chronic Diseases in Northeastern China
}

\author{
Qi Kang ${ }^{\circledR}$, Guojun Kang, Rixin Li, Xiaojing Zhu, Yaqin Yu and Qiong Yu* * \\ Department of Epidemiology and Biostatistics, School of Public Health, Jilin University, Changchun 130021, \\ China; kangqi17@mails.jlu.edu.cn (Q.K.); kanggj17@mails.jlu.edu.cn (G.K.); rxli17@mails.jlu.edu.cn (R.L.); \\ zhuxj17@mails.jlu.edu.cn (X.Z.); yuyaqin5540@163.com (Y.Y.) \\ * Correspondence: yuqiong@jlu.edu.cn; Tel.: +86-431-8561-9451; Fax: +86-431-8564-5486
}

Received: 27 September 2018; Accepted: 16 November 2018; Published: 21 November 2018

\begin{abstract}
Background: Gallbladder diseases are common in Jilin, China. However, there have been few previous studies on this disease. Our study used the chronic disease database in Jilin Province to study the factors correlated with gallbladder diseases. Methods: A total of 21,435 people were selected from the Jilin Province adult chronic disease survey conducted in 2012. Multistage stratified random cluster sampling was used in this cross-sectional study. Multiple logistic regression analysis was used to explore the independent associations of different factors with gallbladder diseases. Results: There were 1876 people with gallbladder diseases, and the prevalence of the diseases was $8.8 \%$ (males $4.4 \%$, females $12.8 \%$ ). Multivariate logistic regression analysis showed that female (prevalence odds ratio $(\mathrm{POR})=3.13,95 \%$ confidence intervals (CIs): $2.76-3.55)$, older people ( $30-45$ years ( $\mathrm{POR}=2.79$, 95\% CIs: $2.06-3.77$ ), $45-60$ years ( $\mathrm{POR}=4.26,95 \%$ CIs: $3.17-5.73$ ), $60-79$ years (POR $=4.72,95 \%$ CIs: 3.48-6.41)), people living in rural areas ( $\mathrm{POR}=1.65,95 \%$ CIs: 1.49-1.82), smoking (current smoker $(\mathrm{POR}=1.15,95 \%$ CIs: 1.01-1.31), former smoker ( $\mathrm{POR}=1.37,95 \%$ CIs: 1.13-1.66)), high frequency of eating seafood (POR $=0.77,95 \%$ CIs: $0.63-0.93$ ), and high frequency of eating soy products ( $\mathrm{POR}=0.50,95 \%$ CIs: 0.44-0.58) were associated with gallbladder diseases. Conclusions: We found that there were some factors associated with gallbladder disease, and there needs to be further studies to confirm these associations.
\end{abstract}

Keywords: gallbladder disease; relationship; cross-sectional study

\section{Introduction}

With the development of society, our concern about diseases has shifted from the traditional focus on diseases such as cancer to the prevalence of chronic diseases. Indeed, chronic diseases pose a serious threat to human health [1]. Gallbladder disease is a common chronic disease, and its prevalence varies from $4 \%$ to $73 \%$ in different regions [2], bringing serious financial burden to regional governments. Gallbladder diseases are common in the population, especially in some European countries and the United States $[3,4]$. However, there have been few reports regarding the prevalence of gallbladder diseases in Asian countries.

Most of the studies on the related factors of gallbladder diseases have been conducted in western developed countries. Previous studies from the United States have suggested that smoking (both past and current) as well as saturated fat and cholesterol intakes are important risk factors. On the other hand, fruits, vegetables, and foods rich in dietary fiber act as protective factors against gallbladder diseases [5]. Another study from the United States confirmed that the protein intake is associated with lower risk of gallbladder diseases [6]. The results of the above studies show that diet and lifestyle 
habits may be associated with gallbladder diseases. In China, the largest developing country in the world, people's living standards have improved significantly in the past 10 years, and the health problems derived from lifestyle changes have attracted much attention. In particular, the incidence of gallbladder diseases has increased year by year. Therefore, in this study, we conduct a study to investigate the prevalence of gallbladder diseases in the northeastern Chinese population and the association of diet and lifestyle with gallbladder diseases. There have been some earlier studies showing that diabetes and dyslipidemia are related to the occurrence of gallbladder diseases [7-9]. Therefore, we also considered the relationship between several other common chronic diseases and gallbladder diseases in this study.

At present, there is no nationwide survey data on gallbladder diseases in China. Through the investigation of chronic diseases in Jilin Province, we aimed to determine the prevalence of gallbladder diseases in China and find possible association factors for gallbladder disease.

\section{Materials and Methods}

\subsection{Study Population}

This study was part of a cross-sectional survey of chronic diseases in Jilin Province conducted from June 2012 to August 2012 [10,11]. The resident population of Jilin Province was 27.5 million at the time. In order to ensure the representativeness of the survey samples, the differences in economic level, the uniformity of geographic coverage, and the feasibility of the survey were considered in different regions of the province. A multistage stratified random cluster sampling method was adopted. (For more information on crowd sampling, please refer to the articles previously published by our group [12].) According to the sampling plan, a total of 32 districts/counties in nine cities of the province were taken as investigation points. We considered stratification factors, such as urban and rural areas, gender, and age groups, and sampled them according to one thousandth of the province's total population. The number of planned survey samples was 23,050. However, due to the weather, the determined sample size was 21,449 . In the end, 21,435 people completed the investigation. The response rate of subjects in this study was $93 \%$.

Our study was conducted in accordance with the bioethics principles of the Declaration of Helsinki. The study was authorized by the Ethics Committee of Jilin University School of Public Health (Reference Number: 2012-R-011) and the Bureau of Public Health of Jilin Province (Reference Number: 2012-10). All participants voluntarily joined this study with informed consent.

\subsection{Data Collection}

Survey methods were divided into centralized investigation and household survey. The staff at the investigation points made an appointment according to the sample list. The investigators conducted one-on-one surveys with the research subjects. Then, a physical examination, blood glucose test, and blood sample collection were taken of the survey subjects. Within one week after the investigation ended, the investigation team fed back the results and the reports of the lipids test to the investigation points and informed respondents by telephone to collect them. Investigators participated in systematic training and conducted a preinvestigation before the formal investigation. All instruments were corrected before investigation. The survey was verified on site and afterwards to ensure its correctness. We used the parallel double input method to record the data.

The gallbladder diseases we studied included cholecystitis and gallstones. All patients with gallbladder diseases in the past year had been diagnosed by doctors in hospitals above the county level. Doctors diagnosed gallbladder diseases based on cholecystitis and gallstones according to the International Classification of Diseases, 10th Revision (ICD-10) definition. Annual prevalence was used to indicate the distribution of gallbladder disease in the past year. The sociodemographic factors and lifestyle of the respondents were collected by the investigators. People who "never drink" meant they have drunk no more than 12 glasses of alcohol throughout their life. "Never smokers" meant they 
have never smoked in their life or their total number of smokes did not exceed 100 cigarettes. "Former smokers" meant people who have smoked more than 100 cigarettes in their life but do not smoke now. Current smokers meant they have smoked more than 100 cigarettes in their life and still smoke [13].

According to the living standards of residents in Jilin Province, we divided the monthly income per capita of the family into three levels: low ( $<1000$ yuan/month), middle (1000-3000 yuan/month), and high income ( $\geq 3000$ yuan/month). Regular diet referred to eating three meals a day on time. Taste of diet included salty, light, and suitable, and the subjects were allowed to choose their own preferences regarding their tastes. The consumption frequency of vegetables, fruits, meat products, seafood, soy products, and milk were divided into three categories: everyday, sometimes, and few or never. Sometimes eat referred to the intake of the abovementioned foods at a frequency of $\geq 2$ times/week. Few or never eat referred to the frequency of ingestion of these foods being $<2$ times/week. The above criteria came from the recommendations of the local health bureau.

Hypertension was defined as systolic blood pressure (SBP) of $\geq 140 \mathrm{mmHg}$ or diastolic blood pressure (DBP) of $\geq 90 \mathrm{mmHg}$. Both SBP and DBP were taken as the average of two measurements, which were conducted at least $5 \mathrm{~min}$ apart [14]. Hyperlipidemia was defined as total cholesterol (TC) of $\geq 5.2 \mathrm{mmol} / \mathrm{L}$, triglyceride (TG) of $\geq 1.7 \mathrm{mmol} / \mathrm{L}$, high-density lipoprotein cholesterol (HDL-C) of $<1.0 \mathrm{mmol} / \mathrm{L}$, or low-density lipoprotein cholesterol (LDL-C) of $\geq 3.4 \mathrm{mmol} / \mathrm{L}$ [15]. Diabetes was defined as a history of taking hypoglycemic agents and diabetic or fasting blood glucose of $\geq 7.0 \mathrm{mmol} / \mathrm{L} \mathrm{[16]}$.

\subsection{Statistical Analysis}

Data was input in the computer by Epidata (Version 3.1, Odense, Denmark) and analyzed by SPSS (Version 24.0, IBM SPSS, IBM Corp, Armonk, NY, USA). Categorical variables were expressed as frequency. Comparisons between groups with and without gallbladder diseases with regard to sociodemographic, life behaviors, and common chronic diseases were conducted using Rao-Scott $x^{2}$ test. All the variables that significantly differed between the two groups in the univariate analyses were included in Model 2 (multivariate logistic regression) by stepwise method to examine their independent associations with gallbladder disease. Prevalence odds ratio (POR) with $95 \%$ confidence intervals (CIs) was calculated in Model 1 (univariate logistic regression) and Model 2. $p<0.05$ (two-sided) was considered as statistically significant.

\section{Results}

The study involved 21,435 subjects, of whom 10,337 were males and 11,098 were females. The gender ratio (males: females) was 1:1.07, and the average age was $47.07 \pm 13.41$ years (46.16 \pm 13.95 years in males and $47.91 \pm 12.82$ years in females). The annual prevalence of gallbladder diseases was $8.8 \%$ (males $4.4 \%$, females $12.8 \%$ ).

Table 1 shows the relationship between sociodemographic characteristics, living behaviors, and common chronic diseases and gallbladder diseases according to the results of univariate analysis. Variables like gender, age, residence, education, family income, smoking habits, drinking, regular diet, taste of diet, eat breakfast every day, physical exercise, diabetes, hyperlipidemia, and hypertension were correlated with gallbladder diseases as was the intake frequency of fruit, meat, seafood, soy products and milk. In addition, we also analyzed the relationship between sleep time and gallbladder disease and found that sleep duration was also closely related to gallbladder diseases.

Table 1. Sociodemographic characteristics, living behaviors, and common chronic diseases among subjects with and without gallbladder diseases (univariate analysis).

\begin{tabular}{ccccc}
\hline Variable & No Gallbladder Diseases n (\%) & Gallbladder Diseases n (\%) & $\mathbf{x}^{\mathbf{2}}$ & $p$ \\
\hline Female & $9681(49.50 \%)$ & $1417(75.50 \%)$ & 464.77 & $<0.001$ \\
\hline Age & & & & \\
\hline $18-29$ & $2466(12.60 \%)$ & $49(2.60 \%)$ & & \\
$30-44$ & $6112(31.20 \%)$ & $416(22.20 \%)$ & & \\
\hline
\end{tabular}


Table 1. Cont

\begin{tabular}{|c|c|c|c|c|}
\hline Variable & No Gallbladder Diseases n (\%) & Gallbladder Diseases n (\%) & $\mathrm{x}^{2}$ & $p$ \\
\hline $45-59$ & $7375(37.70 \%)$ & $902(48.10 \%)$ & & \\
\hline $60-79$ & $3606(18.40 \%)$ & $509(27.10 \%)$ & & \\
\hline Residence (Rural) & $9110(46.60 \%)$ & $1173(62.50 \%)$ & 174.47 & $<0.001$ \\
\hline Education (year) $>9$ & $8512(43.50 \%)$ & $562(30.00 \%)$ & 128.98 & $<0.001$ \\
\hline Family income (yuan) & & & 160.25 & $<0.001$ \\
\hline$<1000$ & $7289(37.30 \%)$ & 974 (51.90\%) & & \\
\hline $1000-3000$ & $9477(48.50 \%)$ & $713(38.00 \%)$ & & \\
\hline$>3000$ & $2018(10.30 \%)$ & $122(6.50 \%)$ & & \\
\hline Other ${ }^{a}$ & $775(4.00 \%)$ & $67(3.60 \%)$ & & \\
\hline Smoking habits & & & 42.41 & $<0.001$ \\
\hline Never smoker & $11738(60.00 \%)$ & $1254(66.80 \%)$ & & \\
\hline Current smoker & $6259(32.00 \%)$ & $464(24.70 \%)$ & & \\
\hline Former smoker & $1562(8.00 \%)$ & $158(8.04 \%)$ & & \\
\hline Drinking & $6484(33.20 \%)$ & $344(18.30 \%)$ & 173.06 & $<0.001$ \\
\hline Regular diet & $15748(80.50 \%)$ & $1542(82.20 \%)$ & 3.10 & 0.078 \\
\hline Taste of diet & & & 7.94 & 0.019 \\
\hline Suitable & 6817 (34.90\%) & $636(33.90 \%)$ & & \\
\hline Salty & $7437(38.00 \%)$ & $675(36.00 \%)$ & & \\
\hline Light & $5305(27.10 \%)$ & $565(30.10 \%)$ & & \\
\hline Staple food (Rice) & $16709(85.40 \%)$ & $1556(82.90 \%)$ & 8.40 & 0.004 \\
\hline Eat breakfast every day & $16164(82.60 \%)$ & $1650(88.00 \%)$ & 34.39 & $<0.001$ \\
\hline Fresh vegetables & & & 6.40 & 0.041 \\
\hline Few or never eat & $295(1.50 \%)$ & $32(1.70 \%)$ & & \\
\hline Eat everyday & $17482(89.40 \%)$ & $1705(90.90 \%)$ & & \\
\hline Sometimes eat & $1782(9.10 \%)$ & $139(7.40 \%)$ & & \\
\hline Fruit & & & 29.15 & $<0.001$ \\
\hline Few or never eat & $3753(19.20 \%)$ & $457(24.40 \%)$ & & \\
\hline Eat everyday & $10172(52.00 \%)$ & $906(48.30 \%)$ & & \\
\hline Sometimes eat & $5634(28.80 \%)$ & $513(27.30 \%)$ & & \\
\hline Meat & & & 203.63 & $<0.001$ \\
\hline Few or never eat & $4348(22.20 \%)$ & 677 (36.10\%) & & \\
\hline Eat everyday & 7003 (35.80\%) & $464(24.70 \%)$ & & \\
\hline Sometimes eat & $8208(42.00 \%)$ & $735(39.20 \%)$ & & \\
\hline Seafood & & & 105.73 & $<0.001$ \\
\hline Few or never eat & 8859 (45.30\%) & 1078 (57.50\%) & & \\
\hline Eat everyday & 2135 (10.90\%) & $134(7.10 \%)$ & & \\
\hline Sometimes eat & $8565(43.80 \%)$ & $664(35.40 \%)$ & & \\
\hline Soy products & & & 176.27 & $<0.001$ \\
\hline Few or never eat & $1656(8.50 \%)$ & $332(17.70 \%)$ & & \\
\hline Eat everyday & $12018(61.40 \%)$ & $1002(53.40 \%)$ & & \\
\hline Sometimes eat & $5885(30.10 \%)$ & $542(28.90 \%)$ & & \\
\hline Milk & & & 67.03 & $<0.001$ \\
\hline Few or never eat & $12045(61.60 \%)$ & $1335(71.20 \%)$ & & \\
\hline Eat everyday & $3214(16.40 \%)$ & $228(12.20 \%)$ & & \\
\hline Sometimes eat & $4300(22.00 \%)$ & $313(16.70 \%)$ & & \\
\hline Physical exercise & & & 40.40 & $<0.001$ \\
\hline Often & $5749(29.40 \%)$ & $637(34.00 \%)$ & & \\
\hline Occasionally & $4870(24.90 \%)$ & $350(18.70 \%)$ & & \\
\hline Never & $8940(45.70 \%)$ & 889 (47.40\%) & & \\
\hline Sleep duration & & & 48.73 & $<0.001$ \\
\hline$<7$ & $6923(35.40 \%)$ & $816(43.50 \%)$ & & \\
\hline $7-8$ & $10549(53.90 \%)$ & $887(47.30 \%)$ & & \\
\hline$>9$ & $2087(10.70 \%)$ & $173(9.20 \%)$ & & \\
\hline Diabetes & 1156 (5.90\%) & $191(10.20 \%)$ & 53.02 & $<0.001$ \\
\hline Hyperlipidemia & $358(1.80 \%)$ & $79(4.20 \%)$ & 48.58 & $<0.001$ \\
\hline Hypertension & 3122 (16.00\%) & 486 (25.90\%) & 120.92 & $<0.001$ \\
\hline
\end{tabular}

\footnotetext{
a "Other" indicates that the subjects did not provide an answer.
} 
We included these significant factors in Model 2 by stepwise method. Our analyses revealed that female (POR $=3.13,95 \%$ CIs: $2.76-3.55)$, older people (30-45 years ( $\mathrm{POR}=2.79,95 \%$ CIs: $2.06-3.77)$, 45-60 years $(\mathrm{POR}=4.26,95 \%$ CIs: $3.17-5.73), 60-79$ years $(\mathrm{POR}=4.72,95 \%$ CIs: $3.48-6.41)$ ), people living in rural areas (POR $=1.65,95 \%$ CIs: $1.49-1.82$ ), smoking (current smoker (POR $=1.15,95 \%$ CIs: 1.01-1.31), former smoker ( $\mathrm{POR}=1.37,95 \%$ CIs: 1.13-1.66)), the consumption frequency of seafood (eat every day (POR $=0.77,95 \%$ CIs: $0.63-0.93)$, sometimes eat $(\mathrm{POR}=0.84,95 \%$ CIs: $0.76-0.94)$ ), and consumption frequency of soy products (eat every day ( $\mathrm{POR}=0.50,95 \%$ CIs: $0.44-0.58$ ), sometimes eat ( $\mathrm{POR}=0.56,95 \%$ CIs: 0.48-0.65)) were associated with gallbladder diseases (Table 2).

Table 2. Prevalence odds ratio and $95 \%$ confidence intervals for correlates of gallbladder diseases to no gallbladder diseases (multivariate logistic regression).

\begin{tabular}{ccccc}
\hline \multirow{2}{*}{ Variable } & Gallbladder Diseases $\mathbf{( n = 1 8 7 6 )}$ & Model 1 & Model 2 \\
\cline { 2 - 5 } & $\mathbf{n}$ & $\mathbf{\%}$ & POR (95\% CIs) & POR (95\% CIs) \\
\hline Residence (Rural) & 1173 & 62.50 & $1.91(1.74-2.11)$ & $1.65(1.49-1.82)$ \\
\hline Female & 1417 & 75.50 & $3.15(2.83-3.51)$ & $3.13(2.76-3.55)$ \\
\hline Age & & & & \\
\hline $18-29$ & 49 & 2.60 & 1.00 & 1.00 \\
$30-44$ & 416 & 22.20 & $3.43(2.54-4.62)$ & $2.79(2.06-3.77)$ \\
$45-59$ & 902 & 48.10 & $6.16(4.60-8.24)$ & $4.26(3.17-5.73)$ \\
$60-79$ & 509 & 27.10 & $7.10(5.28-9.57)$ & $4.72(3.48-6.41)$ \\
\hline Smoking habits & & & & 1.00 \\
\hline Never-smoker & 1254 & 66.80 & 1.00 & $1.15(1.01-1.31)$ \\
Current smoker & 464 & 24.70 & $0.69(0.62-0.78)$ & $1.37(1.13-1.65)$ \\
Former smoker & 158 & 8.04 & $0.95(0.80-1.13)$ & \\
\hline Seafood & & & & 1.00 \\
\hline Few or never eat & 1078 & 57.50 & 1.00 & $0.77(0.63-0.93)$ \\
Eat everyday & 134 & 7.10 & $0.52(0.43-0.62)$ & $0.84(0.76-0.94)$ \\
Sometimes eat & 664 & 35.40 & $0.64(0.58-0.71)$ & \\
\hline Soy products & & & 1.00 & 1.00 \\
\hline Few or never eat & 332 & 17.70 & $0.42(0.36-0.48)$ & $0.50(0.44-0.58)$ \\
Eat everyday & 1002 & 53.40 & & \\
Sometimes eat & 542 & 28.90 & & \\
\hline
\end{tabular}

\section{Discussion}

Gallbladder diseases seriously affect the quality of life of patients. In this cross-sectional study, we investigated the annual prevalence of gallbladder diseases and related factors. The annual prevalence of adult gallbladder diseases in China's Jilin Province was 8.8\% (4.4\% for men and 12.8\% for women). A survey based on America of gallbladder diseases also yielded similar results $[17,18]$, but the results of an investigation based on the prevalence of gallbladder diseases in India were lower than ours [19]. However, the two studies were very different from our research. Firstly, Americans are diverse, and there have previously been reports that ethnicity is also an important factor in the association of gallbladder diseases. Secondly, the Indian study included gallstones and gallbladder cancer, i.e., the definition of gallbladder diseases was different from ours. Therefore, the above two studies do not provide much reference to us, and a study for the Chinese population was necessary. Our findings are mainly applicable to the population of northern China but have an important reference value for the study of gallbladder diseases in other parts of China.

In line with most studies, we found females had a higher correlation with gallbladder diseases than males $[5,20]$. Some researchers have found that the history of reproductive health, multiple births, and oral contraceptives increase the risk of gallbladder diseases [21,22]. The reports from these 
literatures show that some female hormones make them more susceptible to gallbladder diseases than males. The reason for this phenomenon may also be the existence of some special genes in the female body, making them more susceptible to gallbladder diseases than males.

Few scholars have compared the prevalence of gallbladder diseases between city and rural areas. In this study, we found that there was a greater correlation between people living in rural areas and gallbladder diseases compared to those living in city areas. The reason for this result may be that, despite of the level of hygiene and medicine, people living in rural areas have a single diet compared to city people. In rural China, as people's living standards improve, more and more people are starting to eat more meat and regard this as a symbol of quality of life rather than paying attention to a reasonable mix of diet. It is well known that some specific diets usually have connection to certain diseases.

Elderly people were at higher risk of gallbladder diseases than young people. This conclusion was consistent with others studies [23,24]. A possible reason for the result may be the marked aging of the function of organs, meaning resistance to the disease among the elderly is limited. There is also a possibility that older people suffer from a variety of chronic diseases at the same time, and other diseases promote the occurrence of gallbladder diseases.

In good agreement with other studies, we found that smoking is associated with gallbladder diseases. However, its biological mechanism remains unclear $[25,26]$. Other studies have shown that smoking may affect serum lipid and lipoprotein concentrations, and these serological changes may be associated with gallbladder diseases [27]. In our study, we divided smoking habits into three categories: current smokers, former smokers, and never-smokers. We found that former smokers were 1.37 times more likely to have gallbladder diseases than those who had never smoked, and current smokers were 1.15 times more likely to have gallbladder diseases than those who had never smoked. The reason for these results may be that we did not count the duration of smoking in this survey. Therefore, there may have been cases where those who had quitted smoking had smoked for a longer period than those who are currently smoking. The mechanisms by which smoking is associated with gallbladder diseases are complex and require further study.

Our results suggested that the higher the frequency of intake of seafood and soy products, the lower was the likelihood of gallbladder diseases. Some studies have shown that vegetables protein intake is associated with lower risk of gallbladder diseases and that there is no association between animal protein intake and risk of gallbladder diseases [6,28]. Seafood contains large amounts of unsaturated fatty acids, most of which are long-chain polyunsaturated fatty acids, and can reduce the cholesterol saturation in the bile, meaning the ability of bile to dissolve cholesterol is always within the normal range [29]. At the same time, seafood and soy products contain less triglycerides and cholesterol, which are also conducive to maintaining the normal metabolism of bile [30]. All these are good for maintaining the normal function of bile. Therefore, we believe that regular intake of seafood and soy products may reduce the occurrence of gallbladder disease.

Some studies have investigated the association between sleep duration and chronic diseases. Among them, sleep duration and gallbladder disease has been shown to be related [31]. In our study, we also included sleep duration in the univariate analysis. However, we did not find a similar association in multivariate analysis. The reason for this variance may be because previous studies only included people in the 18-59 age group.

This research comprised a large sample size, and the sample was also sufficiently representative. However, the study still had some limitations. First, this study was a cross-sectional study with the primary purpose being to describe the annual prevalence of gallbladder disease and to find possible associated factors; therefore, it did not test or validate the cause hypothesis. Second, although this was a large epidemiological survey, there were still some meaningful variables that were not included in the questionnaire. Third, some variables such as smoking, drinking, and some dietary factors were subjectively reported by the subjects and were not the result of objective testing, meaning there may have been some bias. Finally, the results of this study can only represent the annual prevalence of 
gallbladder disease in the population of northern China. Therefore, the results should be cautiously used when explaining the annual prevalence of gallbladder disease in other parts of the country.

\section{Conclusions}

The results of our study suggest that demographic characteristics and dietary intake are associated with gallbladder disease. In particular, female and older people have significant correlations with gallbladder disease. At the same time, intake of seafood and soy products is also associated with gallbladder disease. A larger research is needed in the future to confirm these findings.

Author Contributions: Q.K. and Q.Y. came up with the original idea for the study and carried out the design. G.K. and Q.Y. provided valuable insights regarding the methodological approach and organization of the manuscript. Q.K., G.K., R.L., and X.Z. carried out the statistical analysis and reviewed the consistency of data included in the paper. Q.K. drafted the manuscript. Y.Y. and Q.Y. revised the manuscript. All authors read and approved the final manuscript.

Funding: This research was funded by [Natural Science Foundation of China] grant number [81673253], [Projects of International Cooperation and Exchanges NSFC] grant number [81320108025], [Norman Bethune Program of Jilin university] grant number [2015227] and [Scientific Research Foundation of the Health Bureau of Jilin Province, China] grant number [2011Z116].

Acknowledgments: This research was supported by the Natural Science Foundation of China (grant no. 81673253), the Projects of International Cooperation and Exchanges NSFC (no. 81320108025), Norman Bethune Program of Jilin university (Grant Number: 2015227), and the Scientific Research Foundation of the Health Bureau of Jilin Province, China (Grant Number: 2011Z116). The authors would like to thank the teachers and students of Jilin University for their epidemiological investigation.

Conflicts of Interest: The authors declare that there is no conflict of interests.

\section{References}

1. Millett, C. Sick Societies: Responding to the Global Challenge of Chronic Disease. Int. J. Epidemiol. 2012, 41, 574. [CrossRef]

2. Stinton, L.M.; Shaffer, A.E. Epidemiology of Gallbladder Disease: Cholelithiasis and Cancer. Gut Liver 2012, 6, 172-187. [CrossRef] [PubMed]

3. Cen, L.; Pan, J.; Zhou, B.; Yu, C.; Li, Y.; Chen, W.; Shen, Z. Helicobacter Pylori infection of the gallbladder and the risk of chronic cholecystitis and cholelithiasis: A systematic review and meta-analysis. Helicobacter 2017, 23, e12457. [CrossRef] [PubMed]

4. Takahashi, T.; Shivapurkar, N.; Riquelme, E.; Shigematsu, H.; Reddy, J.; Suzuki, M.; Miyajima, K.; Zhou, X.; Bekele, B.N.; Gazdar, A.F. Aberrant promoter hypermethylation of multiple genes in gallbladder carcinoma and chronic cholecystitis. Clin. Cancer Res. 2004, 10, 6126-6133. [CrossRef] [PubMed]

5. Figueiredo, J.C.; Haiman, C.; Porcel, J.; Buxbaum, J.; Stram, D.; Tambe, N.; Cozen, W.; Wilkens, L.; Le, L.M.; Setiawan, V.W. Sex and ethnic/racial-specific risk factors for gallbladder disease. BMC Gastroenterol. 2017, 17, 153. [CrossRef] [PubMed]

6. Lander, E.M.; Wertheim, B.C.; Koch, S.M.; Chen, Z.; Hsu, C.H.; Thomson, C.A. Vegetable protein intake is associated with lower gallbladder disease risk: Findings from the women's health initiative prospective cohort. Prev. Med. 2016, 88, 20-26. [CrossRef] [PubMed]

7. Chhabra, A. Gallbladder Disease in Type-2 Diabetes Mellitus Patients. Int. J. Med. Dent. Sci. 2013, 2, 7-15. [CrossRef]

8. Boland, L.L.; Folsom, A.R.; Rosamond, W.D. Hyperinsulinemia, dyslipidemia, and obesity as risk factors for hospitalized gallbladder disease. A prospective study. Ann. Epidemiol. 2002, 12, 131-140. [CrossRef]

9. Boland, L.L.; Folsom, A.R.; Boerwinkle, E. Apolipoprotein E genotype and gallbladder disease risk in a large population-based cohort. Ann. Epidemiol. 2006, 16, 763-769. [CrossRef] [PubMed]

10. Yu, Q.; Pang, B.; Liu, R.; Rao, W.; Zhang, S.; Yu, Y. Appropriate Body Mass Index and Waist-hip Ratio Cutoff Points for Overweight and Obesity in Adults of Northeast China. Iran. J. Public Health 2017, 46, 1038-1045. [PubMed] 
11. Wang, S.; Wu, Y.; Ungvari, G.S.; Ng, C.H.; Forester, B.P.; Gatchel, J.R.; Chiu, H.F.K.; Kou, C.; Fu, Y.; Qi, Y.; et al. Sleep duration and its association with demographics, lifestyle factors, poor mental health and chronic diseases in older Chinese adults. Psychiatry Res. 2017, 257, 212-218. [CrossRef] [PubMed]

12. Rao, W.; Su, Y.; Yang, G.; Ma, Y.; Liu, R.; Zhang, S.; Wang, S.; Fu, Y.; Kou, C.; Yu, Y. Cross-Sectional Associations between Body Mass Index and Hyperlipidemia among Adults in Northeastern China. Int. J. Environ. Res. Public Health 2016, 13, 516. [CrossRef] [PubMed]

13. Schoenborn, C.A.; Adams, P.E. Health behaviors of adults: United States, 2005-2007. Vital Health Stat. 2010, 10,1-132.

14. Sun, S.; Lu, F.; Sun, Y.; Zhao, Y.; Liu, Z.; Wang, S. 2010 Chinese guidelines for the management of hypertension. Chin. J. Hypertens. 2011, 39, 579-615. [CrossRef]

15. Dong, X.; Liu, Y.; Yang, J.; Sun, Y.; Chen, L. Efficiency of anthropometric indicators of obesity for identifying cardiovascular risk factors in a Chinese population. Postgrad. Med. J. 2011, 87, 251-256. [CrossRef] [PubMed]

16. Alberti, K.G.; Eckel, R.H.; Grundy, S.M.; Zimmet, P.Z.; Cleeman, J.I.; Donato, K.A.; Fruchart, J.C.; James, W.P.; Loria, C.M.; Smith, S.C., Jr. Harmonizing the metabolic syndrome: a joint interim statement of the International Diabetes Federation Task Force on Epidemiology and Prevention; National Heart, Lung, and Blood Institute; American Heart Association; World Heart Federation; International A. Circulation 2009, 120, 1640-1645. [CrossRef] [PubMed]

17. Everhart, J.E.; Khare, M.; Hill, M.; Maurer, K.R. Prevalence and ethnic differences in gallbladder disease in the United States. Gastroenterology 1999, 117, 632-639. [CrossRef]

18. Simon, J.A.; Hudes, E.S. Serum ascorbic acid and gallbladder disease prevalence among US adults: The Third National Health and Nutrition Examination Survey (NHANES III). Arch. Intern. Med. 2000, 160, 931-936. [CrossRef] [PubMed]

19. Unisa, S.; Roy, T.K. Field Study of Gallbladder Diseases in Rural Gangetic Basin of North India, Impact of Environmental and Life Style Risk Factors. 2010. Available online: http:/ / paa2010.princeton.edu/papers / 102064 (accessed on 15 June 2018).

20. Mcmichael, A.J.; Baghurst, P.A. A Case-Control Study of Smoking and Gallbladder Disease: Importance of Examining Time Relations. Epidemiology 1992, 3, 519-522. [CrossRef] [PubMed]

21. Strom, B.L.; Tamragouri, R.N.; Morse, M.L.; Lazar, E.L.; West, S.L.; Stolley, P.D.; Jones, J.K. Oral contraceptives and other risk factors for gallbladder disease. Clin. Pharmacol. Ther. 1986, 39, 335-341. [CrossRef] [PubMed]

22. Gomati, A.; Elafi, S.; Rafe, H. A study on the Risk factors for Gallbladder diseases in El-khoms Teaching Hospital, Libya. IOSR-JDMS 2014, 13, 1-4. [CrossRef]

23. Friedman, G.D.; Kannel, W.B.; Dawber, T.R. The epidemiology of gallbladder disease: Observations in the Framingham study. J. Chronic Dis. 1966, 19, 273-292. [CrossRef]

24. Sunilkumar, K.B.; Kulkarni, V.; Suresh, K.K.; Chandrasekhar, H.R. Prevalence of Various Gallbladder lesions in Central Karnataka Region-A Four Year Prospective Study. Indian J. Public Health Res. Dev. 2015, 6, 256-260. [CrossRef]

25. Liu, B.; Balkwill, A.; Roddam, A.; Brown, A.; Beral, V. Separate and joint effects of alcohol and smoking on the risks of cirrhosis and gallbladder disease in middle-aged women. Am. J. Epidemiol. 2009, 169, 153-160. [CrossRef] [PubMed]

26. Okamoto, M.; Yamagata, Z.; Takeda, Y.; Yoda, Y.; Kobayashi, K.; Fujino, M.A. The relationship between gallbladder disease and smoking and drinking habits in middle-aged Japanese. J. Gastroenterol. 2002, 37, 455-462. [CrossRef] [PubMed]

27. Dagfinn, A.; Vatten, L.J.; Paolo, B. Tobacco smoking and the risk of gallbladder disease. Eur. J. Epidemiol. 2016, 31, 643-653.

28. Catala, I.; Juste, C.; Boehler, N.; Ferezou, J.; Andre, M.; Riottot, M.; Lutton, C.; Lafont, H.; Bornet, F.; Corring, T. Cholesterol crystallization in gall-bladder bile of pigs given cholesterol-beta-cyclodextrin-enriched diets with either casein or soyabean concentrate as protein sources. Br. J. Nutr. 2000, 83, 411-420. [PubMed]

29. Pasternak, A.; Bugajska, J.; Szura, M.; Walocha, J.A.; Matyja, A.; Gajda, M.; Sztefko, K.; Gil, K. Biliary Polyunsaturated Fatty Acids and Telocytes in Gallstone Disease. Cell Transplant. 2017, 26, 125-133. [CrossRef] [PubMed] 
30. Hu, F.B.; Manson, J.E.; Willett, W.C. Types of dietary fat and risk of coronary heart disease: A critical review. J. Am. Coll. Nutr. 2001, 20, 5-19. [CrossRef] [PubMed]

31. Wang, S.; Li, B.; Wu, Y.; Ungvari, G.S.; Ng, C.H.; Fu, Y.; Kou, C.; Yu, Y.; Sun, H.Q.; Xiang, Y.T. Relationship of Sleep Duration with Sociodemographic Characteristics, Lifestyle, Mental Health, and Chronic Diseases in a Large Chinese Adult Population. J. Clin. Sleep Med. 2017, 13, 377-384. [CrossRef] [PubMed]

(C) 2018 by the authors. Licensee MDPI, Basel, Switzerland. This article is an open access article distributed under the terms and conditions of the Creative Commons Attribution (CC BY) license (http:/ / creativecommons.org/licenses/by/4.0/). 